\title{
Can the SARS-CoV-2 infection trigger systemic lupus erythematosus? A case-based review
}

\author{
Abraham Edgar Gracia-Ramos ${ }^{1,2}\left[\right.$ [ $\cdot$ Miguel Ángel Saavedra-Salinas ${ }^{3}$ (i)
}

Received: 12 November 2020 / Accepted: 17 January 2021 / Published online: 4 February 2021

(c) The Author(s), under exclusive licence to Springer-Verlag GmbH, DE part of Springer Nature 2021

\begin{abstract}
Systemic lupus erythematosus (SLE) is an autoimmune and multisystemic chronic inflammatory disease that can affect various organs, including skin, joints, kidneys, lungs and the nervous system. Infectious agents have long been implicated in the pathogenesis of SLE. The new viral infection caused by severe acute respiratory syndrome coronavirus 2 (SARS-CoV-2) has shown that, in genetically predisposed patients could trigger the presentation or exacerbation of the autoimmune disease. We herein report a case of a 45-year-old man who presented respiratory symptoms, bilateral pleural effusion, ascites, splenomegaly, severe thrombocytopenia and renal failure with proteinuria and hematuria. SARS-CoV-2 PCR confirmed the COVID-19 diagnosis. We diagnosed the patient with SLE based on the clinical manifestations and positive immunological markers (2019 European League Against Rheumatism/American College of Rheumatology, score of 18). Glucocorticoid pulses were administered to the patient, which improved renal function. However, thrombocytopenia was also refractory to IV immunoglobulin and rituximab, so the patient underwent splenectomy. Through a systematic search of the medical literature, we retrieved two cases with newly onset SLE and five cases with previous SLE diagnosis that showed activity of the disease due to SARS-CoV-2 infection. We herein present a systemic review of these cases and discuss the clinical manifestations that could help to the diagnosis of this clinical condition.
\end{abstract}

Keywords Lupus erythematosus systemic $\cdot$ Severe acute respiratory syndrome coronavirus $2 \cdot$ Coronavirus · COVID-19

\section{Introduction}

Systemic lupus erythematosus (SLE) is a multisystemic, chronic and potentially fatal autoimmune disease that causes alterations in various steps of the immune cascade,

Abraham Edgar Gracia-Ramos

aegr_1982@outlook.com; dr.gracia.dmm@gmail.com

Miguel Ángel Saavedra-Salinas

miansaavsa@gmail.com

1 Department of Internal Medicine, General Hospital, National Medical Center "La Raza", Instituto Mexicano del Seguro Social, Av. Jacaranda S/N, Col. La Raza, Del. Azcapotzalco, C.P. 02990 Mexico City, Mexico

2 Department of Internal Medicine, Hospital Regional de Alta Especialidad de Zumpango, Carretera Zumpango-Jilotzingo No. 400, Barrio Santiago, Segunda Sección, C.P. 55600 Zumpango, Estado de México, Mexico

3 Department of Rheumatology, Hospital de Especialidades Dr. Antonio Fraga Mouret, National Medical Center "La Raza”, Instituto Mexicano del Seguro Social, Mexico City, Mexico resulting in a remarkable heterogeneity of clinical manifestations, including those at the cutaneous, musculoskeletal, hematological, renal and neurological levels, among others $[1,2]$. The natural history of SLE ranges from an insidious slow and progressive disease, with exacerbations and remissions, to an acute and rapidly fatal disease. It is one of the most common autoimmune diseases, especially among Afro-Americans, Hispanic and Asian populations. The highest frequency of SLE is observed in women in the reproductive period with a female:male ratio of up to 9:1 [1]. The leading causes of death in SLE patients include renal disease, severe disease flares with significant organ damage and infections [3]. The most recent 2019 European League Against Rheumatism (EULAR)/American College of Rheumatology (ACR) classification criteria include positive antinuclear antibody (ANA) positive antinuclear antibodies as mandatory criteria followed by criteria grouped into 7 clinical domains (constitutional, hematological, neuropsychiatric, mucocutaneous, serous, musculoskeletal, renal) and 3 immunological domains (antiphospholipid antibodies, complement proteins, SLE-specific antibodies) weighted from 2 
to 10 . Patients accumulating $\geq 10$ points are classified with SLE with a sensitivity of $96.1 \%$ and a specificity of $93.4 \%$ [4].

The etiology of SLE remains unknown, although both exogenous and endogenous factors have been found to influence its pathogenesis, with infectious agents playing an important role in genetically predisposed individuals [5]. Various pathogens have been implicated in the development of SLE, especially viruses such as human endogenous retroviruses, Epstein-Barr virus, parvovirus B19, cytomegalovirus and human immunodeficiency virus type 1 [6]. These agents can contribute to the pathogenesis of the disease by triggering autoimmunity through various mechanisms including structural or functional molecular mimicry, encoding proteins that induce cross-reactive immune responses to self-antigens or modulate antigen processing, activation, or apoptosis of B and $\mathrm{T}$ cells, macrophages or dendritic cells [6-8]. Coronavirus disease 19 (COVID-19), a newly emerged respiratory disease caused by severe acute respiratory syndrome coronavirus 2 (SARS-CoV-2), has recently become pandemic. The COVID-19 pathophysiology has shown that in genetically predisposed patients, it could lead to the presentation or exacerbations of autoimmune diseases [9]. Hence, we present the case of a patient who developed SLE probably triggered by a SARS-CoV-2 infection and we also conducted a review of the literature.

\section{Case report}

A 45-year-old Hispanic man was admitted in the emergency department with dry cough, malaise, myalgia, arthralgia, fever and swelling of the legs. The patient's symptoms started 3-weeks before with recurrent episodes of fever, dry cough, myalgia and arthralgia, which had worsened during the last week and adding edema of the legs. A general practitioner prescribed azithromycin, acetylsalicylic acid, paracetamol, and oseltamivir 2 weeks after the onset of symptoms. The patient was previously healthy, without a history of drug abuse or a family history of autoimmune diseases. Initial physical examination revealed a body temperature of $37.1{ }^{\circ} \mathrm{C}$, a blood pressure of $116 / 70 \mathrm{mmHg}$, a pulse of 102 beats per minute, and a respiratory rate of 22 breaths per minute. Pulse oximetry showed an oxygen saturation of $92 \%$ in room air. His throat was hyperemic. No abnormalities were detected on auscultation of the lungs and heart. No lymphadenopathy or hepatosplenomegaly were found. $\mathrm{He}$ had edema of the lower extremities $(1+)$. Initial laboratory studies showed hyperazotemia (creatinine $2.53 \mathrm{mg} / \mathrm{dL}$ [normal range (NR) $0.7-1.2 \mathrm{mg} / \mathrm{L}$ ], urea $107.96 \mathrm{mg} / \mathrm{dL}$ (NR $10-50 \mathrm{mg} / \mathrm{dL})$, hypoalbuminemia (2.5 g/dL, NR 3.4-4.8 g/ $\mathrm{dL})$, thrombocytopenia (13.000/ $\mu \mathrm{L}$, NR 150.000-450.000/ $\mu \mathrm{L})$, mild anemia ( $11.8 \mathrm{~g} / \mathrm{dL}, \mathrm{NR} 14.0-18.0 \mathrm{~g} / \mathrm{dL})$, prolonged activated partial thromboplastin time (39.2 s, NR 24.0-35 s) and elevated fibrinogen (706 mg/dL, NR 200-400 mg/dL). Chest X-ray showed bilateral reticular pattern with vascular enlargement (Fig. 1). Abdominal ultrasonography revealed small bilateral pleural effusion, peritoneal fluid and splenomegaly. The SARS-CoV-2 polymerase chain reaction (PCR) with nasopharyngeal swab was positive.

The patient was admitted to the isolation area for COVID19 patients of the Department of Internal Medicine; therapy with dexamethasone $6 \mathrm{mg} I V /$ day, ceftriaxone $1 \mathrm{gr} \mathrm{IV}$ twice daily, furosemide $20 \mathrm{mg}$ IV twice daily and paracetamol 1 gr PO was started. Further investigation revealed D-dimer of $3437 \mathrm{ng} / \mathrm{mL}$ (NR 0.0-222 ng/mL), C-reactive protein (CRP) of $154.09 \mathrm{mg} / \mathrm{L}$ (NR 0.0-5.0), ferritin level of $1752.21 \mathrm{ng} /$ $\mathrm{mL}$ (NR $17.9-464.0 \mathrm{ng} / \mathrm{mL}$ ), urinalysis with albuminuria $(0.25 \mathrm{~g} / 24 \mathrm{~h})$ and erythrocyturia. Immunologic test showed signs of autoimmune disease, including antinuclear antibodies (ANA) 1:1280 positive antinuclear antibodies with coarse speckled pattern, anti-double-stranded (ds) DNA 23 IU/ $\mathrm{mL}$ (negative $<20 \mathrm{IU} / \mathrm{mL}$ ), anti-SSA $83.44 \mathrm{IU} / \mathrm{mL}$ (negative $<20 \mathrm{IU} / \mathrm{mL}$ ), anti-SSB $26.754 \mathrm{IU} / \mathrm{mL}$ (negative $<20 \mathrm{IU} /$ $\mathrm{mL}$ ), complement C3 $71.4 \mathrm{mg} / \mathrm{dL}$ (NR 90-177 mg/dL) and immunoglobulin IgG $1790 \mathrm{mg} / \mathrm{dL}$ (NR 770-1510 mg/dL). Serology tests for human immunodeficiency virus (human T-lymphotropic virus-1 and virus-2), hepatitis B virus and hepatitis $\mathrm{C}$ virus were negative. TORCH profile was positive to anti-rubella IgG antibodies and anti-herpes simple IgG antibodies (Table 1). The clinical and laboratory findings led to the diagnosis of SLE (2019 ACR/EULAR score of 18).

With the initial treatment, the patient showed improvement in constitutional and respiratory symptoms. However, his renal function worsened [blood urea nitrogen (BUN) $125.42 \mathrm{mg} / \mathrm{dL}$, urea $281.5 \mathrm{mg} / \mathrm{dL}$ ] with persistent severe thrombocytopenia $(<10,000 / \mu \mathrm{L})$ and abnormal liver function tests [serum glutamate-oxalate transaminase (SGOT)

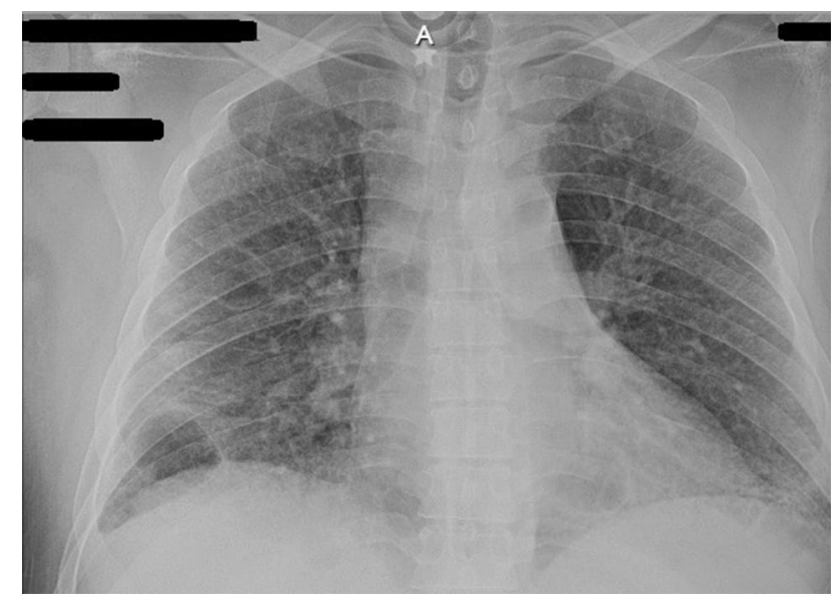

Fig. 1 Chest X-ray showed bilateral reticular pattern with vascular enlargement 
Table 1 Laboratory characteristics of the patient

\begin{tabular}{|c|c|c|c|}
\hline Laboratory values (reference range and units) & Initial values & Peak/nadir values & After treatment \\
\hline Hemoglobin $(14.0-18.0 \mathrm{~g} / \mathrm{dL})$ & 11.8 & 10.2 & 10.6 \\
\hline Platelets $(150.000-450.000 / \mu \mathrm{L})$ & 13,000 & 5000 & 34,000 \\
\hline Leukocytes $(4000-13,500 / \mu \mathrm{L})$ & 7250 & 10,330 & 4610 \\
\hline 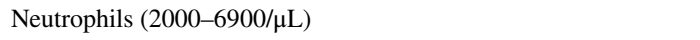 & 4240 & 8780 & 3360 \\
\hline Lymphocytes $(600-3400 / \mu \mathrm{L})$ & 1890 & 770 & 1040 \\
\hline Creatinine $(0.7-1.2 \mathrm{mg} / \mathrm{dL})$ & 2.53 & 2.8 & 0.25 \\
\hline Urea $(10-50$ mg/dL) & 107.96 & 281.5 & 45.2 \\
\hline BUN (7.0-18 mg/dL) & 58.41 & 125.42 & 20.89 \\
\hline Creatinine kinase (38-174 U/L) & 32.82 & 195 & 28 \\
\hline SGOT (10-50 U/L) & 38.12 & 66.8 & 16.9 \\
\hline SGTP (10-40 U/L) & 20.69 & 70.9 & 12.4 \\
\hline Alkaline phosphatase (40-129 U/L) & 165 & 362 & 120 \\
\hline GGT (8.0-61.0 U/L) & 65 & 352 & 92 \\
\hline LDH (240-480 U/L) & 439.7 & 444.7 & 139 \\
\hline Ferritin $(17.9-464.0 \mathrm{ng} / \mathrm{mL})$ & 1752.21 & & \\
\hline CRP $(0.0-5.0 \mathrm{mg} / \mathrm{L})$ & 154.09 & 167.36 & 6.19 \\
\hline D-dimer $(0.0-22 \mathrm{ng} / \mathrm{mL})$ & 3437 & 3983 & \\
\hline Fibrinogen $(200-400 \mathrm{mg} / \mathrm{dL})$ & 706 & 604 & 307 \\
\hline INR $(0.73-1.26)$ & 1.2 & 1.1 & 0.96 \\
\hline PT (11.8-15.6 s) & 13.9 & 11.8 & 11.1 \\
\hline aPTT $(24.0-35.0 \mathrm{~s})$ & 39.2 & 34.2 & 26.8 \\
\hline ANA (negative titers $<1: 20$ ) & \multicolumn{2}{|c|}{$\begin{array}{l}\text { Titers 1:1280, coarse speck- } \\
\text { led pattern }\end{array}$} & \\
\hline Anti-double-stranded DNA antibodies (negative $<20 \mathrm{U} / \mathrm{mL}$ ) & \multicolumn{2}{|c|}{23} & \\
\hline Anti-Smith (negative $<20 \mathrm{U} / \mathrm{mL}$ ) & \multicolumn{2}{|l|}{1.655} & \\
\hline Anti-RNP (negative < $20 \mathrm{U} / \mathrm{mL}$ ) & \multicolumn{2}{|l|}{3.319} & \\
\hline Anti-SSA (negative < $20 \mathrm{U} / \mathrm{mL}$ ) & \multicolumn{2}{|l|}{83.44} & \\
\hline Anti-SSB (negative $<20 \mathrm{U} / \mathrm{mL}$ ) & \multicolumn{2}{|l|}{26.754} & \\
\hline Anticardiolopin IgM (negative $<20 \mathrm{U} / \mathrm{mL}$ ) & \multicolumn{2}{|l|}{$<2.0$} & \\
\hline Anticardiolipin IgG (negative $<20 \mathrm{U} / \mathrm{mL}$ ) & \multicolumn{2}{|l|}{$<2.0$} & \\
\hline Complement C3 (90-177 mg/dL) & \multicolumn{2}{|l|}{71.4} & \\
\hline Complement C4 (15-45 mg/dL) & \multicolumn{2}{|l|}{16} & \\
\hline Immunoglobulin IgG (770-1510 mg/dL) & \multicolumn{2}{|l|}{1790} & \\
\hline Immunoglobulin IgA (134-297 mg/dL) & \multicolumn{2}{|l|}{192.9} & \\
\hline Immunoglobulin IgM (67-208 mg/dL) & \multicolumn{2}{|l|}{78.3} & \\
\hline Anti-HIV 1/HIV 2 antibodies (negative $<1.0 \mathrm{~S} / \mathrm{CO}$ ) & \multicolumn{2}{|l|}{0.1} & \\
\hline HBsAg (negative $<1.0 \mathrm{~S} / \mathrm{CO}$ ) & \multicolumn{2}{|l|}{0.14} & \\
\hline HCAc (negative $<1.0 \mathrm{~S} / \mathrm{CO}$ ) & \multicolumn{2}{|l|}{0.07} & \\
\hline Anti-toxoplasma gondii IgG antibodies (negative $<1.0 \mathrm{U} / \mathrm{mL}$ ) & \multicolumn{2}{|l|}{0.13} & \\
\hline Anti-toxoplasma gondii IgM antibodies (negative $<0.79$ INDEX) & \multicolumn{2}{|l|}{0.21} & \\
\hline Anti-rubella IgG antibodies (negative $<10 \mathrm{U} / \mathrm{mL}$ ) & \multicolumn{2}{|l|}{37.41} & \\
\hline Anti-rubella IgM antibodies (negative $<0.80 \mathrm{~S} / \mathrm{CO}$ ) & \multicolumn{2}{|l|}{0.25} & \\
\hline Anti-herpes simplex IgG antibodies (negative $<0.9 \mathrm{U} / \mathrm{mL}$ ) & \multicolumn{2}{|l|}{20.4} & \\
\hline Anti-herpes simplex IgM antibodies (negative < 1.0 S/CO) & \multicolumn{2}{|l|}{0.6} & \\
\hline Anti-cytomegalovirus IgG antibodies (negative $<0.5 \mathrm{U} / \mathrm{mL}$ ) & \multicolumn{2}{|l|}{201.5} & \\
\hline Anti-cytomegalovirus IgM antibodies (negative $<0.69$ INDEX) & 0.178 & & \\
\hline Urine albumin (negative, $\mathrm{g} / 24 \mathrm{H}$ ) & 0.25 & & \\
\hline Urine hemoglobin (negative, $\mathrm{mg} / \mathrm{dL}$ ) & 250 & & \\
\hline
\end{tabular}

aTTP activated partical thromboplastin time, ANA antinuclear antibodies, Anti-dsDNA anti-double-stranded deoxyribonucleic acid antibodies, Anti-RNP anti-ribonucleoprotein, $B U N$ blood urea nitrogen, $C R P$ C-reactive protein, $G G T$ gamma-glutamyl transaminase, $H B s A g$ hepatitis B surface antigen, $H C A c$ hepatitis $\mathrm{C}$ antibody, $H I V$ human immunodeficiency virus, $L D H$ lactate dehydrogenase, $P T$ prothrombine time, $S G O T$ serum glutamate-oxalate transaminase, SGTP serum glutamate-pyruvate transaminase 
66.8 U/L, serum glutamate-pyruvate transaminase (SGTP) $70.9 \mathrm{U} / \mathrm{L}$, alkaline phosphatase $362 \mathrm{U} / \mathrm{L}$, gamma-glutamyl transaminase (GGT) $352 \mathrm{U} / \mathrm{L}]$. The patient received pulse methylprednisolone therapy (1 g IV for 5 days) and chloroquine $150 \mathrm{mg}$ per day was initiated. After this treatment, kidney and liver functions improved markedly. Due to persistent severe thrombocytopenia, the patient was administered IV immunoglobulin ( $2 \mathrm{mg} / \mathrm{kg} /$ for 4 days) and rituximab $600 \mathrm{mg}$ (3 doses) without a satisfactory response $(<10,000 /$ $\mu \mathrm{L})$. Finally, the patient underwent splenectomy, raising his platelets to $38,000 / \mu \mathrm{L}$ and without evidence of bleeding. The patient was discharged on prednisone $60 \mathrm{mg}$ daily and chloroquine $150 \mathrm{mg}$ per day.

\section{Search strategy}

According to the published guidance on narrative reviews [10], a literature search from December 2019 (when SARSCoV-2 was first reported) to November 2, 2020 in PubMed and Scopus with MeSH search terms "Lupus Erythematosus Systemic" and "Severe Acute Respiratory Syndrome Coronavirus 2" or "Coronavirus" or "COVID-19" was performed. Case reports of patients with SARS-COV-2 infection and diagnosis of SLE (new onset or previous SLE diagnosis) with activity triggered (defined as a measurable increase in disease activity in one or more organ or systems involving new or worse clinical signs and symptoms and/or laboratory measurements) were included. Publications without restrictions in the language were eligible for inclusion. We extracted the following data from the selected papers: age, sex, SLE duration, clinical symptomatology, laboratory tests (including immunologic profile), antiviral therapy, SLE therapy, complications and outcome.

\section{Discussion}

A total of 78 potentially relevant citations were identified. After removing the duplicate citations, title and abstracts of 48 articles were evaluated, and 9 relevant articles were reviewed to detail. Seven case reports were found to be relevant for this research (Fig. 2) [11-17]. With the present report, a total of 8 cases were included for this review. Of the 8 patients (including ours), $6(75 \%)$ were women with a median age of 48 (range 18-85) (Table 2). Five cases $(63 \%)$ occurred in patients with a previous history of SLE (one case with associated antiphospholipid syndrome and another case with end-stage renal disease secondary to WHO Class IV lupus nephritis) $[11,12,14,16,17]$. The nonspecific clinical manifestations reported were fever in 5 cases $[12,13,16,17$ and the present report], malaise in 3 cases [13,17 and the present report], 1 case with headache [14] and 1 case with myalgia and arthralgia [present report]. Organ-specific manifestations reported were pulmonary (cough in 4 cases $[13,14,17$ and present report] $)$, shortness of breath in 4 cases
Fig. 2 Flow chart of study selection

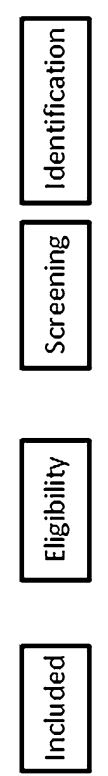

* The MeSH research terms used in search strategy: "Lupus Erythematosus, Systemic", "severe acute respiratory syndrome coronavirus 2", "Coronavirus", "COVID-19". 


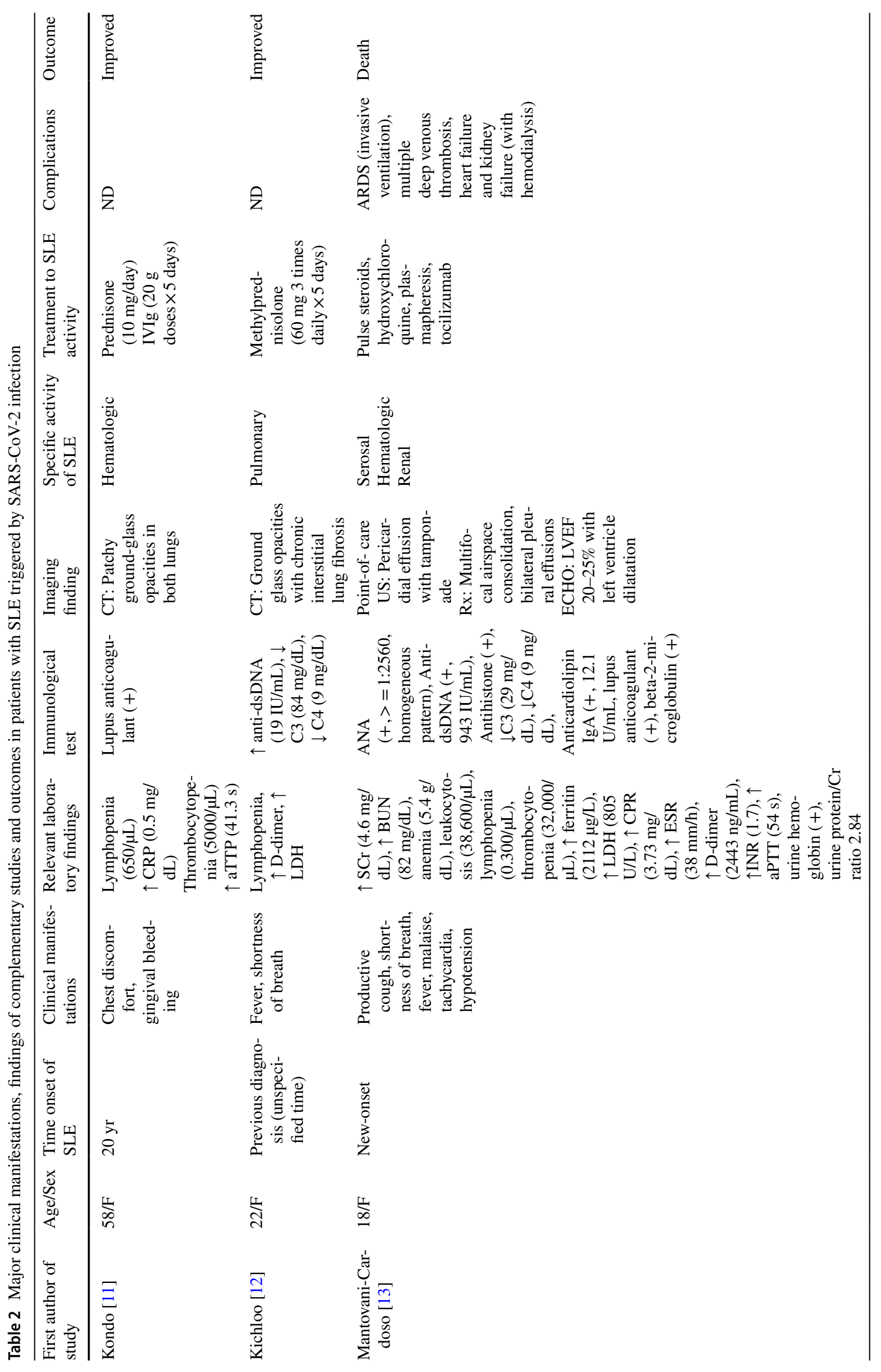




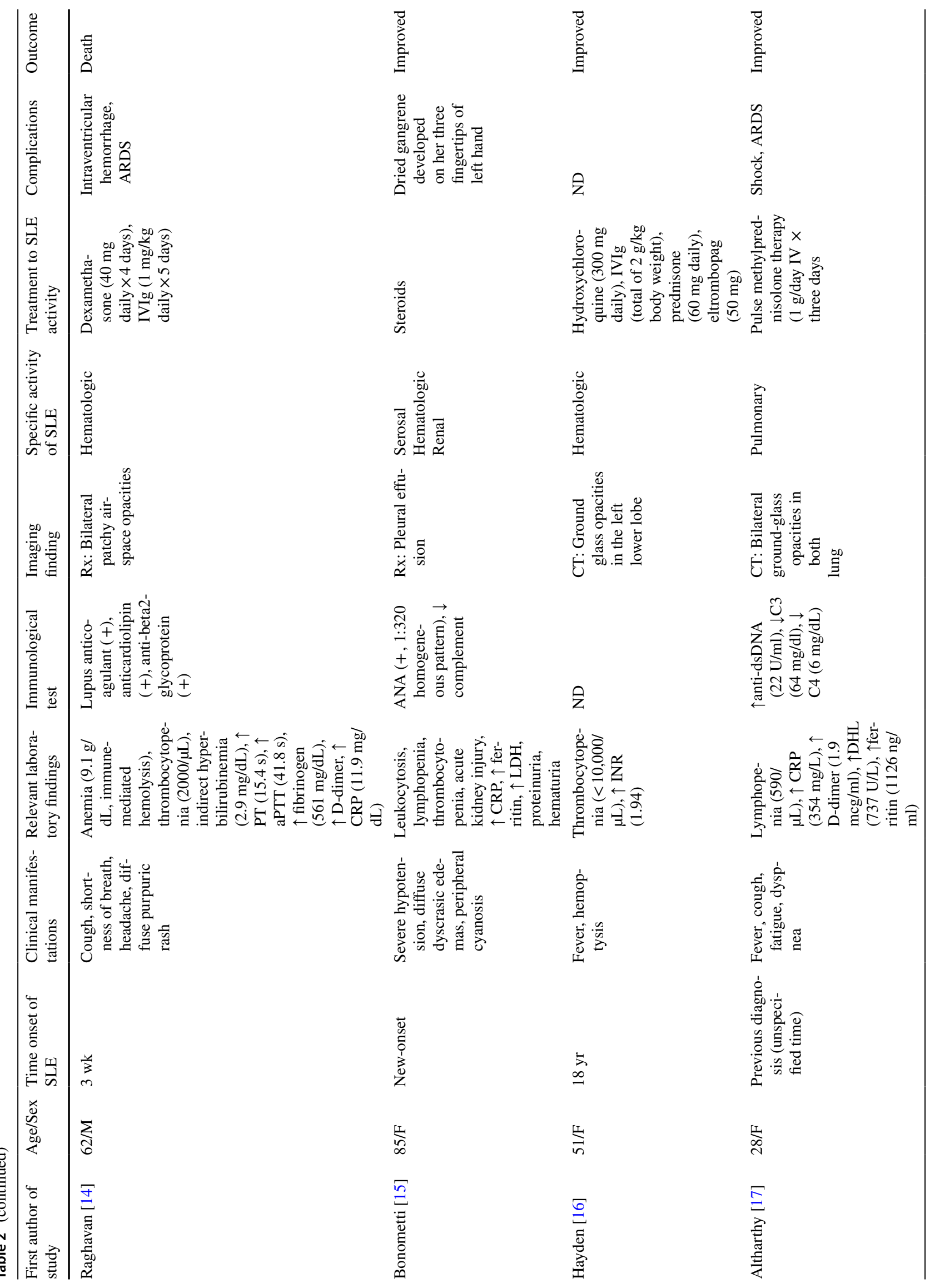




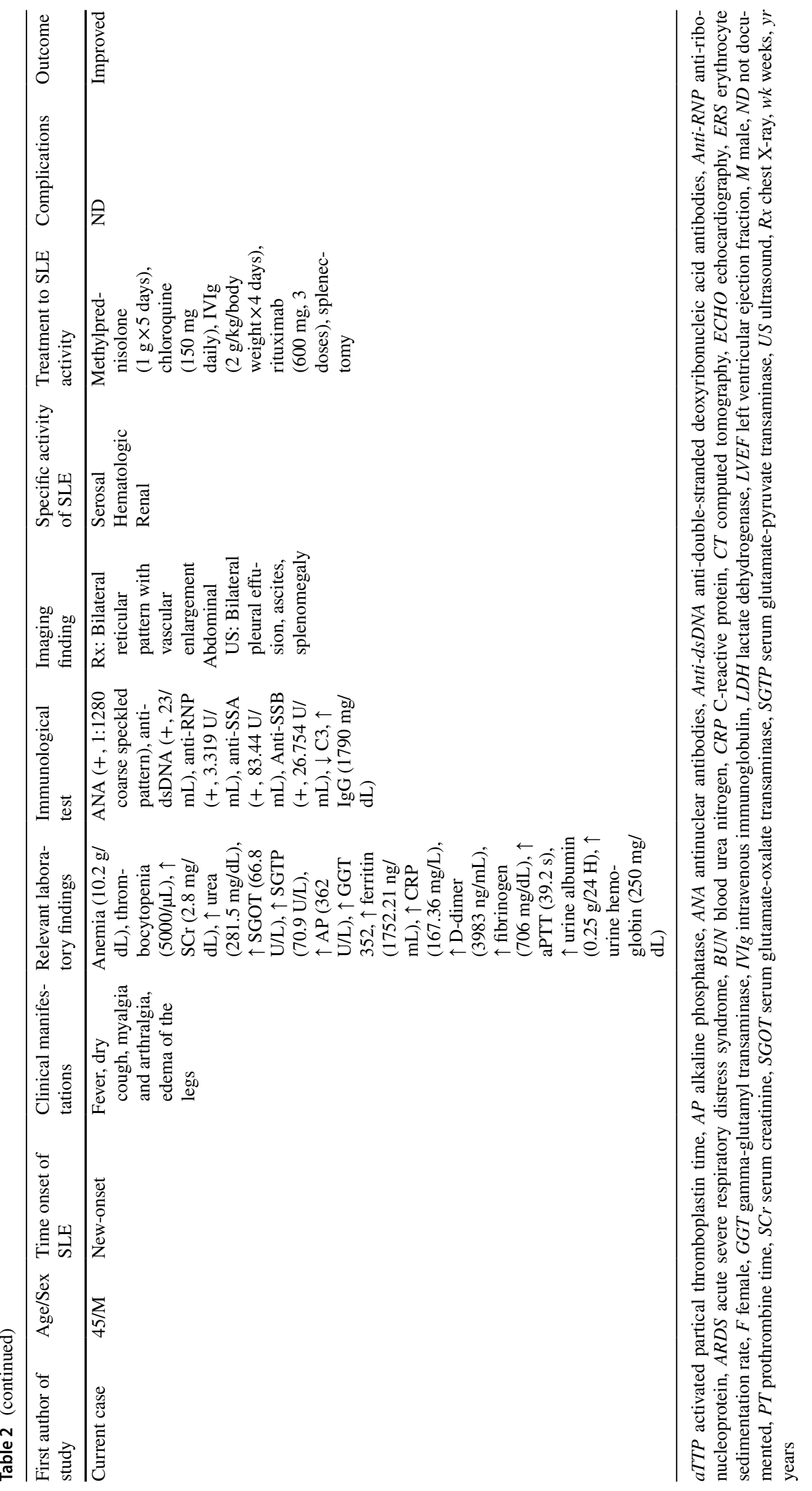


[12-14], chest discomfort in 1 case [11] and peripheral cyanosis in 1 case [15]), cardiovascular ( 2 cases with circulatory collapse $[13,15]$ ), hematological (hemoptysis in 1 case [16], gingival bleeding in 1 case [11] and 1 case with diffuse purpuric rash [14]) and renal (edema in 2 cases [15 and the present report]) features. Laboratory findings included anemia in 3 cases (one with confirmed immune hemolysis) $[13,14$ and the present report], thrombocytopenia in 6 cases (5 with severe thrombocytopenia $[<50.000 / \mu \mathrm{L}]$ ) $[11,13-16$ and the present report], lymphopenia in 5 cases [11-13, 15 , 17], hyperazotemia in 4 cases $[13,15,17$ and the present report], increased transaminases in 1 case [present report], hyperbilirubinemia in 1 case [14], increased LDH in 4 cases $[12,13,15,17]$, elevated CRP in 6 cases $[11,13-15,17$ and the present report], hyperferritinemia in 4 cases $[13,15,17$ and the present report], prolonged prothrombin time in 1 case [14], prolonged activated partial thromboplastin time in 4 cases $[11,13,14$ and the present report], prolonged international normalized ratio in 2 cases [13, 16], elevated fibrinogen in 2 cases [14 and the present report], elevated D-dimer in 5 cases [12-14,17 and present report], proteinuria in 3 cases [13,15 and the present report] and hematuria in 3 cases [13,15 and the present report]. Immunological tests showed low serum complement in 5 cases [12-14,17 and the present report], high titer of ANA in 4 cases [13,15 and the present report], high titers of anti-dsDNA antibodies in 4 cases $[12,13,17$ and the present report], anti-Ro/SSA antibodies in 1 case [present report], positive anti-La/SSB antibodies in 1 case [present report], positive lupus anticoagulant in 3 cases $[11,13,14]$, positive anticardiolipin antibodies in 2 cases $[13,14]$, and positive anti- $\beta 2$-glycoprotein 1 antibodies in 2 cases $[13,14]$. Reported SLE activity was hematologic in 6 patients [11,13-16 and the present report], serosal in 3 patients $[13,15$ and the present report], renal in 3 patients [13,15 and the present report] and pulmonary in two patients $[13,17]$. The diagnosis of SARS-CoV-2 infection was made by PCR test in 7 patients $[11-14,16,17]$ and by serologic test in 1 patient [15]. Imaging studies found bilateral pleural effusion in 3 cases [13,15 and the present report], patchy ground-glass opacities in 5 cases (one with chronic interstitial lung fibrosis) [12-14, 16, 17], bilateral reticular pattern with vascular enlargement in 1 case [present report], pericardial effusion with tamponade in 1 case [13] and impaired left ventricle ejection fraction in 1 case [13]. The treatment used in patients with a previous diagnosis of SLE included hydroxychloroquine-belimumab-azathioprinewarfarin [16]; hydroxychloroquine-mycophenolic acid [12, 17]; prednisone [11]; and no therapy [14]. Treatment for COVID-19 was administered in 4 patients, remdesivir in 1 case [14], tocilizumab in 1 case [13], lopinavir/ritonavir and ribavirin in 1 case [17] and dexamethasone in 1 case [present report]. On the other hand, SLE activity was treated with glucocorticoids in all cases; IVIg was added in 4/7 patients
[11,14,17 and the present report]; antimalarial drugs in 3/7 patients $[13,16$, and the present report]; rituximab in $2 / 7$ patients [14 and the present report]; plasmapheresis [13] and eltrombopag [16] in one patient each. Our patient underwentsplenectomy for refractory thrombocytopenia. Four patients required 3 or more drugs for the management of SLE activity $[13,14,16$ and the present report]. Five patients required supplemental oxygen [12-15, 17]; 3 patients developed severe acute respiratory distress syndrome and used invasive ventilation $[13,14,17]$. One case presented intraventricular hemorrhage due to severe thrombocytopenia [14]; and one case presented multiple deep venous thrombosis (DVT), with heart failure, and kidney failure that warranted hemodialysis [13]. Death was reported in 2 cases (one case with severe acute respiratory distress syndrome, heart failure, kidney injury and multiple DVT [13] and one case with severe acute respiratory distress syndrome and intraventricular hemorrhage [14]).

The diagnosis of recent onset or reactivation of SLE can be challenging in patients with SARS-CoV-2 infection because both diseases share some characteristics. The spectrum of presentation of COVID-19 ranges from asymptomatic individuals or mild symptoms to severe-critical illness [18]. According to a recently published systematic review that included 148 articles $(24,410$ patients), the most prevalent constitutional symptoms in patients with confirmed COVID-19 were fever (78\%), fatigue (31\%), myalgia (17\%) and arthralgia (11\%) [19]. In SLE patients, fatigue (80-100\%), arthralgia (90\%), fever (over 50\%) and myalgia are the most prevalent constitutional symptoms [20]. These symptoms are nonspecific, and therefore do not allow any differentiation between these diseases.

Pulmonary manifestations are very common in patients with SLE, with $50-70 \%$ of patients affected by some pulmonary complication throughout their disease [21]. However, acute pulmonary pneumonitis is an uncommon (1-2\%) manifestation of SLE (although in about half of patients with acute lupus pneumonitis, this is the first manifestation of SLE) [21, 22]. In one case series, the most common presenting symptoms of lupus pneumonitis included fever, cough, dyspnea, hypoxia and lung crepitations [23]. In patients with COVID-19, the main respiratory symptoms reported are cough (57\%), dyspnea (23\%) and chest pain (7\%) [19]. Both diseases showed a ground-glass appearance by CT [21, 24]. Due to these similarities, and given the current pandemic state by SARS-CoV-2, respiratory symptoms should be attributed to COVID-19 unless the patient does not respond to empiric treatment for pneumonia and when extrapulmonary features of SLE are noted (e.g., malar rash, oral ulcers, alopecia, polyserositis, abnormal urine sediment, renal failure, hemocytopenias, thrombophilia, lymphadenopathy, splenomegaly, joint swelling). In the present review, the respiratory manifestations were attributed to SARS-CoV-2 
infection (including ARDS in 2 patients), except 2 patients diagnosed with lupus pneumonitis in whom this diagnosis was considered only after a lack of response to initial treatment for COVID-19. On the other hand, pleural effusion is uncommon in COVID-19. In a systematic review that included 55 studies, pleural effusion detected by chest CT scan was observed in only $11 \%$ of patients [24]. Pleuritis is the most common pulmonary complication in patients with SLE. Clinically apparent pleural effusion has been reported in up to $50 \%$ of patients with SLE and may be found in up to $93 \%$ of patients in necropsy studies [25]. In the present review, pleural effusion was reported in $37.5 \%$ of cases and its presence was associated to activity of SLE.

The most frequently reported blood count abnormality in patients with SARS-CoV-2 infection is lymphopenia, which occurs in $35 \%$ to $83 \%$ of cases [26]. However, lymphopenia is present in $75 \%$ of SLE patients with active disease [27]. Therefore, this finding is not useful for a differential diagnosis between both diseases. Instead, abnormal platelet count should be looked at with attention. Mild thrombocytopenia $(100,000-150,000 / \mu \mathrm{L})$ has been reported in up to $20-36 \%$ of COVID-19 patients but severe thrombocytopenia $(<50,000 / \mu \mathrm{L})$ is unusual and it is associated with the severity of the disease [26, 28]. In a case series of patients admitted to an intensive care unit (ICU) in Wuhan, a platelet count of $<100,000 / \mu \mathrm{L}$ was observed in only $5 \%$ of patients [29]. Thrombocytopenia $<100,000 / \mu \mathrm{L}$ has been reported in $20-40 \%$ of patients with SLE [30]. In the present series, thrombocytopenia was reported in 6 of 7 patients and was considered severe $(<50,000 / \mu \mathrm{L})$ and refractory to treatment in 5 cases. Possible pathophysiological mechanisms of SARS-CoV-2 infection-induced thrombocytopenia include direct attack to the hematopoietic stem/progenitor cells and damage to the lungs by autoantibodies and immune complexes [31]. We speculate that the immuno-mediated mechanisms against platelets in SARS-CoV-2 infection may be more severe in genetically predisposed patients or patients with a history of SLE, which may lead to more severe thrombocytopenia refractory to treatment.

Renal damage in COVID-19 patients has been reported in $>20 \%$ of hospitalized patients and in $>50 \%$ in patients admitted to the ICU [32]. The clinical spectrum of renal disease in COVID-19 ranges from the presence of proteinuria and hematuria to acute kidney injury (AKI) requiring renal replacement therapy [33]. Lupus nephritis represents a leading cause of severe organ involvement observed in $50 \%$ of patients [34]. The clinical presentation and laboratory findings in LN range from "silent" LN to severe proteinuria and nephrotic syndrome, which can result in AKI. However, patients most commonly present with mild proteinuria and/ or hematuria and, in some cases, leukocyturia [35]. Due to these shared characteristics, kidney injury in a patient with suspected SLE activity infected with SARS-CoV-2 can be challenging. In the present series, 3 cases showed kidney disease; in 2 of them the severity of the kidney injury was not consistent with the respiratory disease caused by COVID-19. Therefore, this can be taken into account when making the differential diagnosis.

In the present review, it was found that glucocorticoids were used as the first line of treatment in all patients, regardless of the type and degree of severity, according to the current guidelines [36]. The treatment with glucocorticoids alone was successful in 2 patients and other 4 needed three or more drugs to achieve the control of SLE. Notably, hematological activity was found to be the main manifestation that was refractory to the standard treatment. Rheumatologists should be aware of this situation in order to act promptly in this case.

The possible mechanisms of autoimmunity following SARS-CoV-2 infection include molecular mimicry (crossreacting epitope between the virus and the host), bystander killing (virus-specific $\mathrm{CD} 8+\mathrm{T}$ cells migrating to the target tissues and exerting cytotoxicity), epitope spreading, viral persistence (polyclonal activation due to the constant presence of viral antigens driving immune-mediated injury) and formation of neutrophil extracellular traps [37]. In patients hospitalized due to SARS-CoV-2 pneumonia, a prevalence of ANA of $35.6 \%$ and lupus anticoagulant of $11.1 \%$ has been reported [38]. Other autoantibodies such as anti-Ro/SSA have also been reported [39]. Therefore, this highlights the ability of SARS-CoV-2 to trigger autoimmunity phenomena, which can lead to onset of SLE or a flare of it.

This review has several limitations owing to its retrospective nature, limited size and heterogeneity. In addition, the SARS-CoV-2 infection is still under study and the spectrum of manifestations that it can cause in patients with a previous or new-onset diagnosis of SLE is still unknown. However, this case series can provide meaningful information regarding the clinical profile, diagnosis and management of this complex situation.

In conclusion, the diagnosis of new onset or flare of SLE in a patient with SARS-CoV-2 infection is a challenge. To our knowledge and derived from the present series, the clinical keys that could help with the differential diagnosis are severe thrombocytopenia, serositis and kidney damage that are not related to the severity of the respiratory disease. The presence of such findings should lead to the determination of immunological markers to confirm or rule out the presence of SLE. The goal should be a prompt diagnosis of SLE activity for a timely initiation of specific treatment.

Author contributions The patient was diagnosed and followed up by AEGR and MASS, and AEGR conceived and planned the case report. Material preparation, data collection and analysis were performed by AEGR and MASS. AEGR wrote the initial draft of the manuscript. MASS revised and edited the manuscript. The final version was read, 
corrected, and approved by both authors, who agreed to be accountable for all aspects of the manuscript.

Funding The authors received no financial support for the research, authorship, and/or publication of this article.

\section{Compliance with ethical standards}

Conflict of interest The authors declared no conflicts of interest.

Ethical approval All procedures performed in studies involving human participants were in accordance with the ethical standards of the institutional and/or national research committee and with the 1964 Helsinki declaration and its later amendments or comparable ethical standards.

Informed consent Written informed consent was obtained from the patient for the publication of this case-based review, in compliance with the COPE best practice guidelines.

\section{References}

1. Kaul A, Gordon C, Crow MK, Touma Z, Urowitz MB, van Vollenhoven R, Ruiz-Irastorza G, Hughes G (2016) Systemic lupus erythematosus. Nat Rev Dis Primers 2:16039. https://doi. org/10.1038/nrdp.2016.39

2. Fava A, Petri M (2019) Systemic lupus erythematosus: diagnosis and clinical management. J Autoimmun 96:1-13. https://doi. org/10.1016/j.jaut.2018.11.001

3. Doria A, Iaccarino L, Ghirardello A, Zampieri S, Arienti S, Sarzi-Puttini P, Atzeni F, Piccoli A, Todesco S (2006) Long-term prognosis and causes of death in systemic lupus erythematosus. Am J Med 119(8):700-706. https://doi.org/10.1016/j.amjme d.2005.11.034

4. Aringer M, Costenbader K, Daikh D, Brinks R, Mosca M, Ramsey-Goldman R, Smolen JS, Wofsy D, Boumpas DT, Kamen DL, Jayne D, Cervera R, Costedoat-Chalumeau N, Diamond B, Gladman DD, Hahn B, Hiepe F, Jacobsen S, Khanna D, Lerstrøm K, Massarotti E, McCune J, Ruiz-Irastorza G, Sanchez-Guerrero J, Schneider M, Urowitz M, Bertsias G, Hoyer BF, Leuchten N, Tani C, Tedeschi SK, Touma Z, Schmajuk G, Anic B, Assan F, Chan TM, Clarke AE, Crow MK, Czirják L, Doria A, Graninger W, Halda-Kiss B, Hasni S, Izmirly PM, Jung M, Kumánovics G, Mariette X, Padjen I, Pego-Reigosa JM, Romero-Diaz J, RúaFigueroa Fernández Í, Seror R, Stummvoll GH, Tanaka Y, Tektonidou MG, Vasconcelos C, Vital EM, Wallace DJ, Yavuz S, Meroni PL, Fritzler MJ, Naden R, Dörner T, Johnson SR (2019) 2019 European League Against Rheumatism/American College of Rheumatology classification criteria for systemic lupus erythematosus. Arthritis Rheumatol 71(9):1400-1412. https://doi. org/10.1002/art.40930

5. Illescas-Montes R, Corona-Castro CC, Melguizo-Rodríguez L, Ruiz C, Costela-Ruiz VJ (2019) Infectious processes and systemic lupus erythematosus. Immunology 158(3):153-160. https://doi. org/10.1111/imm.13103

6. Rigante D, Mazzoni MB, Esposito S (2014) The cryptic interplay between systemic lupus erythematosus and infections. Autoimmun Rev 13(2):96-102. https://doi.org/10.1016/j.autre v.2013.09.004

7. Francis L, Perl A (2010) Infection in systemic lupus erythematosus: friend or foe? Int J Clin Rheumtol 5(1):59-74. https://doi. org/10.2217/ijr.09.72
8. Jara LJ, Medina G, Saavedra MA (2018) Autoimmune manifestations of infections. Curr Opin Rheumatol 30(4):373-379. https://doi.org/10.1097/BOR.0000000000000505

9. Caso F, Costa L, Ruscitti P, Navarini L, Del Puente A, Giacomelli R, Scarpa R (2020) Could Sars-coronavirus-2 trigger autoimmune and/or autoinflammatory mechanisms in genetically predisposed subjects? Autoimmun Rev 19(5):102524. https:// doi.org/10.1016/j.autrev.2020.102524

10. Gasparyan AY, Ayvazyan L, Blackmore H, Kitas GD (2011) Writing a narrative biomedical review: considerations for authors, peer reviewers, and editors. Rheumatol Int 31(11):1409-1417. https://doi.org/10.1007/s00296-011-1999-3

11. Kondo Y, Kaneko Y, Oshige T, Fukui H, Saito S, Okayama M, Kamata H, Ishii M, Hasegawa N, Fukunaga K, Takeuchi T (2020) Exacerbation of immune thrombocytopaenia triggered by COVID-19 in patients with systemic lupus erythematosus. Ann Rheum Dis. https://doi.org/10.1136/annrheumdis-2020218157

12. Kichloo A, Aljadah M, Albosta M, Wani F, Singh J, Solanki S (2020) COVID-19 and acute lupus pneumonitis: diagnostic and treatment dilemma. J Investig Med High Impact Case Rep 8:2324709620933438. https://doi.org/10.1177/232470962093343 8

13. Mantovani Cardoso E, Hundal J, Feterman D, Magaldi J (2020) Concomitant new diagnosis of systemic lupus erythematosus and COVID-19 with possible antiphospholipid syndrome. Just a coincidence? A case report and review of intertwining pathophysiology. Clin Rheumatol 39(9):2811-2815. https://doi.org/10.1007/ s10067-020-05310-1

14. Raghavan S, Gonakoti S, Asemota IR, Mba B (2020) A case of systemic lupus erythematosus flare triggered by severe coronavirus disease 2019. J Clin Rheumatol 26(6):234-235. https://doi. org/10.1097/RHU.0000000000001531

15. Bonometti R, Sacchi MC, Stobbione P, Lauritano EC, Tamiazzo S, Marchegiani A, Novara E, Molinaro E, Benedetti I, Massone L, Bellora A, Boverio R (2020) The first case of systemic lupus erythematosus (SLE) triggered by COVID-19 infection. Eur Rev Med Pharmacol Sci 24(18):9695-9697. https://doi.org/10.26355 /eurrev_202009_23060

16. Hayden A, Vyas-Lahar A, Rella V, Rudinskaya A (2020) Severe refractory thrombocytopenia in a woman positive for coronavirus disease 2019 with lupus and antiphospholipid syndrome. Lupus 29(11):1472-1474. https://doi.org/10.1177/0961203320940389

17. Alharthy A, Faqihi F, Nasim N, Noor A, Akhtar S, Balshi A, Balhamar A, Alqahtani SA, Memish ZA, Karakitsos D (2020) COVID-19 in a patient with a flare of systemic lupus erythematosus: a rare case-report. Respir Med Case Rep 31:101252. https ://doi.org/10.1016/j.rmcr.2020.101252

18. Wu Z, McGoogan JM (2020) Characteristics of and important lessons from the coronavirus disease 2019 (COVID-19) outbreak in China: summary of a report of 72314 cases from the Chinese Center for Disease Control and Prevention. JAMA 323(13):1239_ 1242. https://doi.org/10.1001/jama.2020.2648

19. Grant MC, Geoghegan L, Arbyn M, Mohammed Z, McGuinness L, Clarke EL, Wade RG (2020) The prevalence of symptoms in 24,410 adults infected by the novel coronavirus (SARS-CoV-2; COVID-19): a systematic review and meta-analysis of 148 studies from 9 countries. PLoS ONE 15(6):e0234765. https://doi. org/10.1371/journal.pone.0234765

20. Wallace DJ, Gladman DD (2019) Clinical manifestations and diagnosis of systemic lupus erythematosus in adults. UpToDate. https://www.uptodate.com/contents/clinical-manifestationsand-diagnosis-of-systemic-lupus-erythematosus-in-adults?searc $\mathrm{h}=$ systemic\%20lupus\%20erythematosus\&source=search_resul t\&selectedTitle $=1 \sim 150 \&$ usage_type $=$ default $\&$ display_rank $=1$. Accessed 25 Oct 2020 
21. Hannah JR, D'Cruz DP (2019) Pulmonary complications of systemic lupus erythematosus. Semin Respir Crit Care Med 40(2):227-234. https://doi.org/10.1055/s-0039-1685537

22. Matthay RA, Schwarz MI, Petty TL, Stanford RE, Gupta RC, Sahn SA, Steigerwald JC (1975) Pulmonary manifestations of systemic lupus erythematosus: review of twelve cases of acute lupus pneumonitis. Medicine (Baltimore) 54(5):397-409. https ://doi.org/10.1097/00005792-197509000-00003

23. Wan SA, Teh CL, Jobli AT (2016) Lupus pneumonitis as the initial presentation of systemic lupus erythematosus: case series from a single institution. Lupus 25(13):1485-1490. https://doi. org/10.1177/0961203316646461

24. Sun Z, Zhang N, Li Y, Xu X (2020) A systematic review of chest imaging findings in COVID-19. Quant Imaging Med Surg 10(5):1058-1079. https://doi.org/10.21037/qims-20-564

25. Keane MP, Lynch JP 3rd (2000) Pleuropulmonary manifestations of systemic lupus erythematosus. Thorax 55(2):159-166. https:// doi.org/10.1136/thorax.55.2.159

26. Agbuduwe C, Basu S (2020) Haematological manifestations of COVID-19: from cytopenia to coagulopathy. Eur J Haematol 105(5):540-546. https://doi.org/10.1111/ejh.13491

27. Velo-García A, Castro SG, Isenberg DA (2016) The diagnosis and management of the haematologic manifestations of lupus. J Autoimmun 74:139-160. https://doi.org/10.1016/j.jaut.2016.07.001

28. Lippi G, Plebani M, Henry BM (2020) Thrombocytopenia is associated with severe coronavirus disease 2019 (COVID-19) infections: a meta-analysis. Clin Chim Acta 506:145-148. https://doi. org/10.1016/j.cca.2020.03.022

29. Huang C, Wang Y, Li X, Ren L, Zhao J, Hu Y, Zhang L, Fan G, Xu J, Gu X, Cheng Z, Yu T, Xia J, Wei Y, Wu W, Xie X, Yin W, Li H, Liu M, Xiao Y, Gao H, Guo L, Xie J, Wang G, Jiang R, Gao Z, Jin Q, Wang J, Cao B (2020) Clinical features of patients infected with 2019 novel coronavirus in Wuhan. China Lancet 395(10223):497-506. https://doi.org/10.1016/S0140 $-6736(20) 30183-5$

30. Galanopoulos N, Christoforidou A, Bezirgiannidou Z (2017) Lupus thrombocytopenia: pathogenesis and therapeutic implications. Mediterr J Rheumatol 28(1):20-26. https://doi.org/10.31138 /mjr.28.1.20

31. Zhang Y, Zeng X, Jiao Y, Li Z, Liu Q, Ye J, Yang M (2020) Mechanisms involved in the development of thrombocytopenia in patients with COVID-19. Thromb Res 193:110-115. https:// doi.org/10.1016/j.thromres.2020.06.008

32. Nadim MK, Forni LG, Mehta RL, Connor MJ Jr, Liu KD, Ostermann M, Rimmelé T, Zarbock A, Bell S, Bihorac A, Cantaluppi V, Hoste E, Husain-Syed F, Germain MJ, Goldstein SL, Gupta S, Joannidis M, Kashani K, Koyner JL, Legrand M, Lumlertgul N, Mohan S, Pannu N, Peng Z, Perez-Fernandez XL, Pickkers
P, Prowle J, Reis T, Srisawat N, Tolwani A, Vijayan A, Villa G, Yang L, Ronco C, Kellum JA (2020) COVID-19-associated acute kidney injury: consensus report of the 25th Acute Disease Quality Initiative (ADQI) Workgroup. Nat Rev Nephrol 16(12):747-764. https://doi.org/10.1038/s41581-020-00356-5

33. Hirsch JS, Ng JH, Ross DW, Sharma P, Shah HH, Barnett RL, Hazzan AD, Fishbane S, Jhaveri KD, Northwell COVID19 Research Consortium; Northwell Nephrology COVID-19 Research Consortium (2020) Acute kidney injury in patients hospitalized with COVID-19. Kidney Int 98(1):209-218. https:// doi.org/10.1016/j.kint.2020.05.006

34. Parikh SV, Almaani S, Brodsky S, Rovin BH (2020) Update on lupus nephritis: core curriculum 2020. Am J Kidney Dis 76(2):265-281. https://doi.org/10.1053/j.ajkd.2019.10.017

35. Anders HJ, Saxena R, Zhao MH, Parodis I, Salmon JE, Mohan C (2020) Lupus nephritis. Nat Rev Dis Primers 6(1):7. https://doi. org/10.1038/s41572-019-0141-9

36. Fanouriakis A, Kostopoulou M, Alunno A, Aringer M, Bajema I, Boletis JN, Cervera R, Doria A, Gordon C, Govoni M, Houssiau F, Jayne D, Kouloumas M, Kuhn A, Larsen JL, Lerstrøm K, Moroni G, Mosca M, Schneider M, Smolen JS, Svenungsson E, Tesar V, Tincani A, Troldborg A, van Vollenhoven R, Wenzel J, Bertsias G, Boumpas DT (2019) 2019 update of the EULAR recommendations for the management of systemic lupus erythematosus. Ann Rheum Dis 78(6):736-745. https://doi.org/10.1136/ annrheumdis-2019-215089

37. Shah S, Danda D, Kavadichanda C, Das S, Adarsh MB, Negi VS (2020) Autoimmune and rheumatic musculoskeletal diseases as a consequence of SARS-CoV-2 infection and its treatment. Rheumatol Int 40(10):1539-1554. https://doi.org/10.1007/s0029 6-020-04639-9

38. Gazzaruso C, Carlo Stella N, Mariani G, Nai C, Coppola A, Naldani D, Gallotti P (2020) High prevalence of antinuclear antibodies and lupus anticoagulant in patients hospitalized for SARSCoV2 pneumonia. Clin Rheumatol 39(7):2095-2097. https://doi. org/10.1007/s10067-020-05180-7

39. Fujii H, Tsuji T, Yuba T, Tanaka S, Suga Y, Matsuyama A, Omura A, Shiotsu S, Takumi C, Ono S, Horiguchi M, Hiraoka N (2020) High levels of anti-SSA/Ro antibodies in COVID-19 patients with severe respiratory failure: a case-based review: High levels of antiSSA/Ro antibodies in COVID-19. Clin Rheumatol 39(11):31713175. https://doi.org/10.1007/s10067-020-05359-y

Publisher's Note Springer Nature remains neutral with regard to jurisdictional claims in published maps and institutional affiliations. 